\title{
Laras, Surupan, dan Patet dalam Praktik Menabuh Gamelan Salendro
}

\section{Asep Saepudin ${ }^{1}$}

Jurusan Karawitan, Fakultas Seni Pertunjukan, Institut Seni Indonesia Yogyakarta

\begin{abstract}
ABSTRAK
Tulisan ini membahas tentang peranan laras, surupan, dan patet dalam praktik menabuh gamelan saléndro. Gamelan saléndro termasuk salah satu perangkat gamelan yang terdapat dalam karawitan Sunda. Penyajian gamelan saléndro dalam karawitan Sunda memiliki keunikan tersendiri yang tidak ditemukan pada musik lain yakni terdapat perbedaan laras antara gamelan yang digunakan dengan lagu yang dinyanyikan oleh pesinden (vokalis). Oleh karena itu, tidak mudah untuk menyajikan sebuah lagu dalam permainan gamelan saléndro karena harus memahami terlebih dahulu laras, surupan, dan patet sebagai jembatan bagi perbedaan laras ini agar terjalin nuansa musikal yang harmonis. Berdasarkan hasil analisis dapat disimpulkan bahwa laras, surupan, dan patet memiliki peranan sangat penting dalam praktik bermain gamelan saléndro, sebagai kunci utama yang harus dikuasai seorang pengrawit (lebih khusus bagi seorang perebab) untuk menyajikan lagu atau gending. Selain itu, disimpulkan pula bahwa laras, surupan, dan patet sebagai satu kesatuan yang utuh, memiliki keterkaitan satu sama lainnya dalam praktik menabuh gamelan saléndro.
\end{abstract}

Kata kunci: patet, laras, surupan, saléndro

\begin{abstract}
Laras, Surupan, and Patet in Playing Salendro Gamelan. This paper discusses the role of laras (musical scale), surupan, and patet (Jawa: pathet) concepts in playing salendro gamelan. Salendro gamelan is one of gamelan instruments in Sundanese gamelan music. The performance of salendro gamelan in Sundanese gamelan has its own uniqueness which is not found in other musical genre or characteristics, that there is a different laras between the used gamelan and the song sung by vocalist. Therefore, it is not easy to present a song in a salendro gamelan play because we should understand laras, surupan, and patet concepts for bridging the difference to create the harmonious musical nuance. Based on the result analysis, it may be concluded that laras, surupan, and patet concepts play the important role in playing the salendro gamelan. They are the main keys for gamelan players who should master to play the song or gending. In addition, laras, surupan, and patet concepts as a unity relate to each other in playing the salendro gamelan.
\end{abstract}

Keywords: patet, laras, surupan, saléndro

\section{Pendahuluan}

Penyajian gamelan saléndro dalam karawitan Sunda memiliki keunikan tersendiri sebagai ciri khas/identitas garap karawitannya. Salah satu keunikan penyajiannya adalah terdapat perbedaan laras antara gamelan dengan vokal yang dinyanyikan oleh pesinden. Meskipun gemelan yang digunakan berlaras saléndro, akan tetapi vokalnya tidak berlaras saléndro, bisa berlaras degung, madenda, mandalungan, atau bahkan bisa multi-laras yakni campuran semua laras yang terdapat dalam karawitan Sunda. Hal ini dapat terjadi meskipun dalam lagu yang sama. Menurut Mariko (2007: 91104) perbedaan kedua laras ini disebut dengan laras ganda. Fenomena semacam ini tentunya memiliki perbedaan jika dibandingkan dengan permainan gamelan saléndro dalam karawitan lainnya seperti karawitan Jawa gaya

Alamat korespondensi: Jurusan Karawitan, Fakultas Seni Pertunjukan, Institut Seni Indonesia Yogyakarta.
Jln. Parangtritis Km. 6,5, Sewon, Bantul, Yogyakarta. E-mail: sepskd@gmail.com;. HP: 081227978377 
Surakarta, Yogyakarta, Banyumas, Banyuwangi, maupun karawitan Bali. Pada kelima gaya ini, ketika gamelan yang digunakan berlaras saléndro maka vokal umumnya berlaras saléndro pula.

Hadirnya dua laras atau lebih yang berbeda dalam praktik menabuh gamelan saléndro menjadi tantangan tersendiri bagi para seniman dalam menyajikan sebuah gending atau lagu. Jika seorang pengrawit (khusus perebab) atau pesinden tidak paham terhadap konsep surupan, laras, dan patet, dapat berakibat fatal terhadap jalannya sajian gamelan saléndro. Permasalahan yang sering terjadi dalam penyajian gamelan saléndro, antara lain: sulitnya pesinden untuk memulai ngawih (bernyanyi) lagu yang akan disajikan, laras atau nada-nada hasil suara pesinden tidak bisa harmonis (menyatu) dengan nada-nada dalam gamelan yang digunakan, permainan waditra (instrumen) rebab terasa numpang (miring) dari nada-nada atau dari perangkat gamelan yang digunakan, serta suara pesinden terkesan sumbang (blero=Jawa) dari gamelan yang digunakan. Fenomena semacam ini sering terjadi dalam sajian karawitan Sunda terutama bagi para seniman pemula yang belum pernah mengetahui konsep menabuh dan nyinden dengan menggunakan perangkat gamelan saléndro.

Terjadinya fenomena di atas diakibatkan oleh belum sepenuhnya para pengrawit paham terhadap konsep menabuh gamelan saléndro. Padahal, terdapat berbagai unsur (meliputi patet, laras, dan surupan) yang harus dipertimbangkan dalam menyajikan gamelan saléndro mengingat laras gamelan yang digunakan berbeda dengan laras lagu yang dinyanyikan. Oleh karena itu, untuk memahaminya perlu diuraikan kunci pokok yang mendasari konsep menabuh gamelan saléndro terutama keterkaitan antara konsep laras, surupan, dan patet. Permasalahan yang dibahas dalam tulisan ini adalah peranan dan aplikasi konsep laras, surupan, dan patet dalam praktik menabuh gamelan saléndro.

\section{Gamelan Saléndro}

Gamelan saléndro adalah seperangkat gamelan Sunda yang seluruh waditra memiliki laras saléndro. Penamaan gamelan ini berdasarkan pada laras yang digunakan yaitu laras saléndro. Gamelan saléndro paling sering digunakan oleh para seniman dalam berbagai genre kesenian meskipun dalam karawitan Sunda memiliki beberapa perangkat gamelan seperti gamelan degung dan pélog. Hal ini merupakan salah satu bukti bahwa laras saléndro telah dimiliki oleh masyarakat Sunda sejak lama sebagai bagian laras milik masyarakat Sunda yang telah diwarisi secara turun temurun dari nenek moyangnya.

Gamelan saléndro lebih populer di masyarakat Sunda jika dibandingkan dengan gamelan pélog. Kepopuleran gamelan saléndro hampir sama dengan kepopuleran gamelan degung yang sudah dikenal luas oleh masyarakat Sunda sejak lama. Hal ini dikarenakan oleh sering digunakannya gamelan saléndro dalam setiap pementasan pertunjukan seperti dalam sajian genre kiliningan, topéng banjét, wayang golék, ketuk tilu, serta berbagai iringan tari, baik rumpun tari keurseus maupun tari rakyat.

Pada tahun 1980-an, keberadaan gamelan saléndro lebih populer serta dikenal luas oleh masyarakat ketika di Sunda dihebohkan dengan kehadiran genre baru 'jaipongan' yang di dalam iringannya menggunakan gamelan saléndro. Pada masa itu, para seniman tidak sedikit yang melebur gamelan degung dan pélog untuk dijadikan gamelan berlaras saléndro. Gamelan saléndro lengkap terdiri dari dua buah waditra saron, satu peking, satu demung, satu selentem, seperangkat bonang, seperangkat rincik, seperangkat kenong, satu gambang, satu kempul, satu gong, satu set kendang, satu rebab, dan vokal.

\section{Laras dalam Karawitan Sunda}

Laras termasuk salah satu unsur penting yang ada kaitannya dengan penyajian gamelan saléndro karena lagu-lagu yang dinyanyikan dalam karawitan Sunda menggunakan banyak laras. Laras menjadi kerangka acuan sekaligus bingkai untuk menafsir sistem nada yang melekat atau relevan dengan lagu, gending atau pun iringan lagunya (Irawan, 2014: 21).

Karawitan Sunda memiliki lima yaitu laras yaitu saléndro, pélog, degung, madenda atau sorog, serta mataraman atau mandalungan. Kelima laras ini digunakan dalam sajian karawitan Sunda yang terdapat di berbagai genre kesenian seperti dalam 
kesenian degung, kiliningan, jaipongan, wayang golék, kacapi wanda anyar, dan lain-lain.

Machyar, seorang etnomusikolog Sunda, telah melakukan beberapa kajian untuk membedakan dari kelima laras ini terutama dilihat dari jarak nada/intervalnya. Setelah melalui beberapa tahap kajian selama 50 tahun, sampailah pada kesimpulan bahwa laras dalam karawitan Sunda terdiri dari lima laras dengan memiliki jarak yang berbeda. Menurut Macyar (169: 1-139) dalam konsep laras 17 swara, interval laras saléndro adalah bedantara (beda jarak) antara nada yang satu dengan nada yang lainnya dengan memiliki interval terkecil 210 sen, laras pélog 133 1/3 sen, madenda, degung, dan mataraman interval terkecil 70 sen (Tabel 1).

Laras saléndro disebut sebagai induk laras dari seluruh laras yang ada dalam karawitan Sunda. Berdasarkan hasil konsep laras Machyar, dari laras saléndro inilah dapat melahirkan laras-laras lain seperti laras degung dan madenda. Pernyataan ini diperkuat oleh peneliti berikutnya yakni Harjito yang menyatakan bahwa laras saléndro sebagai induk musik dunia. Dengan metode Matriks "Makro" Sléndro Mikro-nya, Hardjito membuktikan bahwa Laras Sléndro Makro dengan nilai Kempyung ( $\mathrm{K}=720$ sen) dan Laras Sléndro Mikro dengan nilai Kempyung (K=600 sen) dapat mewadahi keberadaan berbagai sistem musik bangsa lain dalam suatu wilayah sistem skema laras musik. Kesimpulannya adalah Laras Sléndro Makro (K=720 sen) merupakan ambang atas konseptual bagi keberadaan berbagai skema musik karena tidak ada lagi skema laras musik lain di atas Laras Sléndro Makro (K= 720 sen). Begitu pula sebaliknya, Laras Sléndro Mikro (K=600 sen) telah terbukti merupakan ambang bawah dari keberadaan berbagai skema musik lain karena tidak ada lagi skema laras musik lain di bawah Laras Sléndro Mikro (K= 600 sen) (Hardjito, 2000: 128-160).

Perlu diketahui bahwa para peneliti di Bandung setelah generasi Machyar mengadakan penelitian tentang laras sebagai langkah dalam menjawab kritikan dari para etnomusikolog Barat terhadap konsep laras Machyar. Deni Hermawan, dkk., mengadakan penelitian laras dengan menggunakan sampel lima puluh dua waditra di seluruh Jawa Barat meliputi tiga puluh set gamelan, sepuluh waditra tarawangsa (rebab dan kacapi), tujuh waditra kacapi indung, dan lima waditra rebab. Namun sangat disayangkan bahwa hasil kesimpulan penelitiannya mengindikasikan bahwa interval Sunda seolah-olah sebagai interval solmisasi dengan nilai terkecil 100 sen (Herdini: 2003: 54-66). Hasil kesimpulan ini tentunya mengingkari fakta-fakta yang ada di lapangan, di antaranya berbedanya laras Sunda dengan Barat serta tidak bisa menyatunya waditra Sunda dengan instrumen Barat (misalnya piano dan kacapi) secara utuh. Meskipun sering terjadi garapan bersama menggunakan instrumen Barat dengan waditra Sunda, akan tetapi umumnya tidak pernah menyatu bahkan terjadi sebuah pemaksaan terhadap laras masing-masing (Hermawan, 2002: 4).

Mengenai hal ini, Saepudin mengkritisi hasil kajian di atas dalam tulisannya "Tasir Ulang atas Hasil Kajian Ulang Teori Laras dan Surupan Karya RMA. Koesoemadinta." Hasil kesimpulannya, Saepudin memberikan lima solusi untuk permasalahan ini yakni: peninjauan kembali hasil kajian laras Machyar; mengelompokkan sampel kajian berdasarkan waktu, tempat, dan fungsi; menggunakan alat ukur interval baru yang disesuaikan dengan kebutuhan laras Sunda; memperhitungkan nilai sen terkecil sebagai ciri khas/identitas budaya musik Sunda; serta menentukan dengan pasti alat ukur yang akan dijadikan standar pengukuran (Saepudin, 2007: 23-32). Terlepas dari berbagai permasalahan tersebut, fenomena laras dalam karawitan Sunda masih memberi peluang untuk didiskusikan secara khusus.

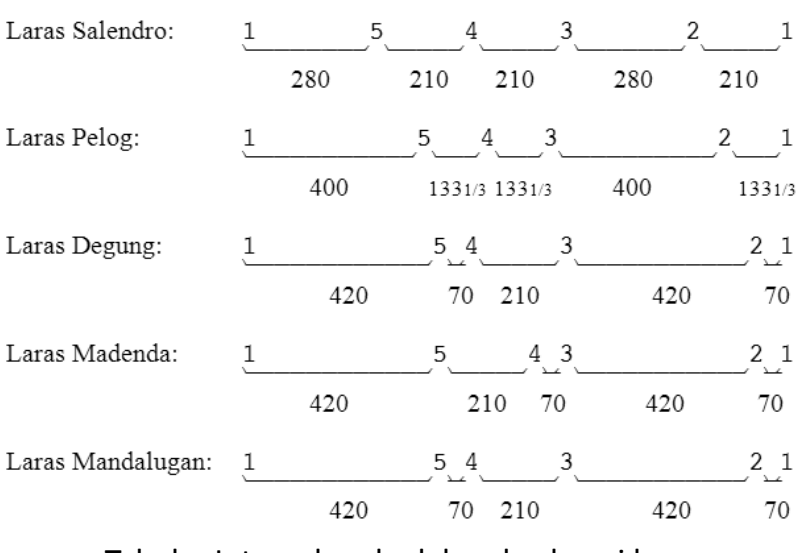

Tabel 1. Interval nada dalam berbagai laras 


\section{Surupan}

Surupan adalah konsep pergeseran tinggi rendahnya nada dasar yang menentukan fungsi nada sebagai nada pokok atau nada sisipan (Suparli, 2010: 159). Meskipun surupan berfungsi sebagai pergeseran tinggi rendah nada dasar, namun hadirnya berbagai surupan dalam laras atau gending yang sama, dapat berpengaruh terhadap berbagai aspek karawitan yakni terhadap gending, garap setiap waditra, karakter lagu, serta nuansa musikal yang dihasilkan. Konsep surupan dalam aplikasinya adalah penempatan nada dasar agar lagu yang dinyanyikan oleh pesinden tetap berada dalam wilayah gamelan yang digunakan meskipun laras lagu tersebut memiliki perbedaan dengan laras gamelan.

Keberadaan konsep surupan dalam praktik menabuh gamelan saléndro sangat penting mengingat lagu-lagu yang terdapat dalam sajian ini memiliki laras yang berbeda. Konsep surupan dapat menuntun sebuah lagu untuk bisa disajikan secara utuh dan harmonis dalam gamelan saléndro, degung, atau gamelan berlaras madenda. Surupan termasuk konsep musikal yang menjembatani sebuah lagu agar dapat disajikan dalam gamelan. Oleh karena itu, pemahaman terhadap konsep surupan sangat penting dikuasai oleh seorang pengrawit terutama perebab (pemain rebab) yang biasa berfungsi sebagai pangkat (intro/pembuka) dan penghias lagu.
Macam-macam surupan dalam karawitan Sunda di antaranya surupan da (nada 1) = Tugu, $m i$ $($ nada 2$)=T u g u, n a($ nada 3$)=T u g u, t i($ nada 4$)=$ Tugu, dan la $($ nada 5$)=$ Tugu. Tugu yang dimaksud dalam surupan ini adalah nada Barang (da) dalam gamelan laras saléndro, sedangkan nada $1(d a), 2$ (mi), $3(n a), 4(t i)$, dan 5 (la) adalah wilayah nada/ laras lagu yang dinyanyikan oleh pesinden. Kelima surupan tersebut bisa berlaku untuk berbagai laras yaitu untuk laras saléndro, pélog, degung, madenda, dan mandalungan.

Penjelasan dari konsep surupan sebagai berikut. Jika lagu yang disajikan seorang pesinden larasnya madenda dengan surupan ti (4) Tugu, hal itu berarti nada ti (4) laras madenda tinggi rendah frekuensinya sama dengan nada TugulBarang/ da (1) dalam laras saléndro. Oleh karena itu, penyusunan tangga nada laras madenda disamakan terlebih dahulu tinggi rendahnya antara nada $t i$ (4) laras madenda dengan nada Tugul da laras saléndro. Penyusunan nada-nada berikutnya menyesuaikan tangga nada laras madenda yang sudah terbentuk dengan diawali dari nada ti (4) laras madenda terlebih dahulu baik untuk nada tinggi maupun nada rendah (Tabel 2).

Pembentukan surupan madenda ti (4) sama dengan Tugu (Tabel 2) menghasilkan tiga nada yang tumbuk (bersamaan) yaitu nada $t i$ (4) laras madenda tumbuk dengan nada TugulBarang (1) laras saléndro, nada la (5) laras madenda tumbuk dengan nada Loloran (2) laras saléndro,

\begin{tabular}{|c|c|c|c|c|c|c|c|c|c|c|c|c|c|c|c|c|c|c|c|c|c|c|c|c|c|c|}
\hline I & \multicolumn{2}{|c|}{$\mathrm{s}$} & \multicolumn{2}{|c|}{$\begin{array}{ll}\mathrm{s} & \mathrm{s} \\
\end{array}$} & \begin{tabular}{l|l}
$\mathrm{s}$ & $\mathrm{s}$
\end{tabular} & $\mathrm{s}$ & \begin{tabular}{l|l}
$\mathrm{s}$ & $\mathrm{s}$
\end{tabular} & \multicolumn{2}{|c|}{$\begin{array}{ll}\mathrm{s} & \mathrm{s}\end{array}$} & $\mathrm{s}$ & \multicolumn{2}{|c|}{\begin{tabular}{l|l|}
$\mathrm{s}$ & $\mathrm{s}$
\end{tabular}} & \begin{tabular}{l|l}
$\mathrm{s}$ & $\mathrm{s}$
\end{tabular} & $\mathrm{s}$ & \multicolumn{2}{|c|}{$\mathrm{s}$} & \begin{tabular}{|l|l|} 
& $s$
\end{tabular} & 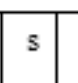 & \multicolumn{2}{|c|}{\begin{tabular}{ll|}
$\mathrm{s}$ & $\mathrm{s}$ \\
\end{tabular}} & \multicolumn{2}{|c|}{$\mathrm{s}$} & & s & \multirow[t]{2}{*}{\begin{tabular}{l|l}
$s$ & 5
\end{tabular}} & \multirow[t]{2}{*}{\begin{tabular}{l|l}
$\mathrm{s}$ & $\mathrm{s}$
\end{tabular}} \\
\hline $\mathbf{R}$ & 1 & & & & & 5 & & & & 4 & & & 3 & & & & & 2 & & & & 1 & & & & \\
\hline $\mathbf{M}$ & $\mathrm{B}$ & & & & & $\mathrm{S}$ & & & & $\mathrm{G}$ & & & & $\overline{\mathrm{P}}$ & & & & $\mathrm{L}$ & & & & $\mathrm{B}$ & & & & \\
\hline D & & & 3 & & & & & & & 2 & 1 & 1 & & & & & & 5 & & & & 4 & 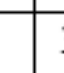 & 3 & & \\
\hline
\end{tabular}

Ket:

$\mathrm{I}=$ interval sebesar $70 \operatorname{sen}(\mathrm{s})$

$$
\mathrm{B}=\text { Barang } / \text { Tugu }
$$

$\mathrm{R}=$ Nada relatif dari laras saléndro

$\mathrm{L}=$ Loloran

$\mathrm{P}=$ Panelu

$\mathrm{M}=$ Nada mutlak laras saléndro

$\mathrm{G}=$ Galimer

$\mathrm{m}=$ Nada-nada laras madenda

$S=$ Singgul

= Nada tumbuk atau surupan ti (4) laras madenda sama dengan Tugu (1) laras saléndro 
serta nada $m i$ (2) laras madenda tumbuk dengan nada Galimer (4) laras saléndro. Berdasarkan data tersebut, terdapat tiga nada saléndro yang bisa dijadikan dasar untuk menentukan gending yang digunakan untuk mengiringi sebuah lagu karena ketiganya berfungsi sebagai kenongan. Gending yang memiliki kenongan ini biasanya terdapat dalam Gending Senggot dengan kenongan nada 1 dan 4, sedangkan gongannya nada 2 . Hal ini akan dibahas lebih rinci dalam pembahasan patet.

Proses pembentukan surupan di atas berlaku pula untuk laras lainnya seperti halnya laras degung. Jika lagu yang dinyanyikan oleh pesinden berlaras degung dengan surupan mi (2) sama dengan Tugu, tinggi rendah frekuensi nada $m i$ (2) laras degung sama dengan tinggi rendahnya nada Tugu (1) laras saléndro. Selanjutnya, pembentukan tangga nada laras degung diawali dari nada mi (2) yang akan membentuk rangkaian nada-nada berikutnya dalam laras degung baik nada rendah maupun nada tinggi (Tabel 3).

Pembentukan surupan degung mi (2) sama dengan Tugu (Tabel 3) menghasilkan dua nada yang tumbuk yaitu nada mi (2) laras degung tumbuk dengan nada Tugu/Barang (1) laras saléndro, nada la (5) laras degung tumbuk dengan nada Galimer (4) laras saléndro. Berdasarkan data tersebut, terdapat dua nada saléndro yang bisa dijadikan dasar untuk menentukan gending yang digunakan dalam mengiringi sebuah lagu karena keduanya berfungsi sebagai kenongan. Gending yang memiliki kenongan ini biasanya terdapat dalam Gending Gendu dengan kenongan nada 1 sedangkan gongannya nada 4 .

Proses terbentuknya surupan dalam berbagai laras secara konseptual semuanya seperti tergambar dalam dua tabel di atas. Konsep surupan ini berperan sebagai jembatan penghubung (titik temu) antara dua laras yang berbeda yaitu laras degung atau madenda atau mandalungan dalam lagu yang dinyanyikan oleh pesinden dengan laras saléndro yang terdapat dalam gamelan yang digunakan untuk mengiringi lagu tersebut. Adapun waditra yang memiliki peranan penting dalam hal ini adalah waditra rebab. Waditra rebab ini selanjutnya bertugas untuk menuntun lagu dari seorang pesinden agar dapat masuk ke dalam gamelan saléndro yang digunakan.

Rebab salah satu fungsinya sebagai pangkat (introduction) dalam permainan gamelan saléndro. Waditra rebab membawa arah lagu pesinden beserta larasnya sejak awal sampai dengan akhir sajian. Biasanya ketika pangkat (buka) dimulai oleh perebab, arah laras dan surupan lagu yang akan dinyanyikan dalam sajian karawitan sudah dapat dibaca dengan jelas baik oleh pesinden maupun pengrawit lainnya. Seorang pesinden sudah diberi jalan terlebih dahulu untuk merasakan laras dan surupan sehingga untuk memulai bernyanyi hanya mengikuti arah lagu yang disajikan oleh perebab.

\begin{tabular}{|l|l|l|l|l|l|l|l|l|l|l|l|l|l|l|l|l|l|l|l|l|l|l|l|l|l|l|l|l|}
\hline I & s & s & s & s & s & s & s & s & s & s & s & s & s & s & s & s & s & s & s & s & s & s & s & s & s & s & s & s \\
\hline R & 1 & & & & & 5 & & & & 4 & & & & 3 & & & & & 2 & & & & $\mathbf{1}$ & & & & & 5 \\
\hline M & B & & & & & S & & & & G & & & P & & & & L & & & & B & & & & S \\
\hline D & & & 1 & & & & & & & 5 & & 4 & & & & 3 & & & & & & & $\mathbf{2}$ & & 1 & & & \\
\hline
\end{tabular}

Ket:

$\mathrm{I}=$ interval sebesar 70 sen $(\mathrm{s})$

$\mathrm{R}=$ Nada relatif dari laras saléndro

$\mathrm{M}=$ Nada mutlak laras saléndro

$\mathrm{m}=$ Nada-nada laras madenda

$$
\begin{aligned}
& \mathrm{B}=\text { Barang/Tugu } \\
& \mathrm{L}=\text { Loloran } \\
& \mathrm{P}=\text { Panelu } \\
& \mathrm{G}=\text { Galimer } \\
& \mathrm{S}=\text { Singgul }
\end{aligned}
$$

= Nada tumbuk atau surupan mi (2) laras degung sama dengan Tugu (1) laras saléndro 


\section{Patet}

Selain laras dan surupan, patet termasuk unsur yang sangat penting dalam sajian gamelan saléndro. Konsep patet berfungsi terutama dalam pembentukan dan penentuan gending-gending yang digunakan untuk mengiringi lagu dalam praktik bermain gamelan saléndro. Gendinggending yang digunakan untuk mengiringi lagu dalam sajian gamelan saléndro secara umum banyak terdapat dalam konsep patet.

Patet adaah penetapan tinggi raras dominan (dasar $=$ patokaningraras) dan tonika (tutugingraras = rénaningraras) dari suatu lagon atau lebih untuk menentukan tinggi rendahnya atau besar kecilnya (ageung-alit) lagon-lagon itu. Lagon sendiri diartikan sebagai letaknya tonika dan dominan dalam pasieupan/tangga nada (Machyar, 1969: 23). Patet juga diartikan wilayah rasa suatu lagu dalam suatu surupan yang diwujudkan oleh rasa nada-nada, disebabkan oleh pengaruh serta fungsi nada-nada tersebut di dalam organisasi yang dibentuk oleh lagu itu (Atik Soepandi, 1995: 160).

Dalam karawitan Jawa, kata patet (pathet) selalu muncul dan menyertai suatu repertoar karawitan (selanjutnya disebut gending), misalnya gending ladrang Clunthang slendro pathet sanga, gending Playon slendro pathet manyuro, gending Ayak-ayak slendro pathet nem, dan lain.lain (Prasetya, 2012: 67). Keberadaan patet dalam karawitan Jawa sangat penting pula untuk menentukan struktur wayang kulit karena berkaitan dengan pembagian adegan yakni pathet nem, patet sanga, dan patet manyura (Sukistono, 2014: 180). Pembagian patet dalam pergelaran wayang kulit merupakan tanda atau pemilah waktu pertunjukan yakni patet nem berlangsung dari pukul 21.00-24.00, patet sanga dimulai dari pukul 24.00-03.00, patet manyura dari pukul 03.00-06.00 (Suhardjono, 2011: 67).

Patet dalam karawitan Sunda memiliki fungsi yang hampir sama dengan karawitan Jawa. Patet dalam karawitan Sunda terdiri dari lima yaitu Patet Nem, Loloran, Manyuro, Sanga, dan Singgul. Kelima patet terbentuk dari hasil skema patet (Tabel 4).

Dalam konsep patet, posisi lagu yang ditandai oleh angka romawi (I, II, III, IV, dan V) memiliki peranan yang sangat penting kaitannya dalam pembentukan gending-gending di Sunda. Posisi lagu adalah posisi yang menunjukkan letak nada yang fungsinya sebagai nada Pancer, Pangagét, Kenongan, dan Gongan. Keempat fungsi ini sebagai kunci pokok untuk menabuh gamelan pélog saléndro. Sebagai contoh, jika posisi lagunya (I dan IV), kenongannya berada di posisi nada 2 dan gonganya nada 5, posisi ini memiliki pancer nada 1 dan pangagét nada 4, sehingga gending tersebut berada dalam wilayah Patet Loloran dengan arkuh lagu (balungan gending) sebagai berikut: Get nada 4, Cer nada 1, Gèt nada 4, Nong nada 2, Gèt nada 4, Cer nada 1, Gèt nada 4, Gong nada 5. Gèt singkatan dari Pangaget, Cer singkatan dari Pancer, Nong singkatan dari Kenongan, Gong singkatan dari Gongan.

Urutan dan posisi nada di atas, merupakan kunci pokok untuk menabuh gamelan pélog saléndro dalam karawitan Sunda yaitu Gét Cer Gét Nong Gét Cer Gét Gong. Waditra yang menabuh arkuh lagu tersebut adalah waditra selentem. Adapun gending yang arkuh lagunya seperti di atas termasuk Gending Catrik. Posisi lagu (I dan IV) Gending Catrik mengisi posisi patokaning laras dan pangrena yaitu nada 2 dan 5 (nada Loloran dan Singul).

Gending-gending lainnya dalam karawitan Sunda dapat terbentuk dengan memperhatikan posisi lagu terlebih dahulu. Posisi lagu (I dan IV) di atas jika digeser ke atas atau ke bawah ke Patet Nem, Manyuro, Sanga, dan Singul dapat membentuk gending baru yang berbeda dari posisi semula. Selain menghasilkan gending baru, secara otomatis pergeseran tersebut dapat menghasilkan nada kenongan dan gongan yang berbeda. Ketika nada kenongan dan gongnnya berbeda, maka akan

\begin{tabular}{|l|c|c|c|c|c|}
\cline { 2 - 6 } \multicolumn{1}{c|}{} & \multicolumn{5}{c|}{ Posisi } \\
\hline \multirow{2}{*}{$\begin{array}{l}\text { Tahapan } \\
\text { Patet }\end{array}$} & $\begin{array}{l}\text { Patoleaning } \\
\text { laras }\end{array}$ & Panglangen & Pangaget & Pangrena & Pancer \\
\cline { 2 - 6 } & I & II & III & IV & V \\
\hline Nem & 1 & 2 & 3 & 4 & 5 \\
\hline Loloran & 2 & 3 & 4 & 5 & 1 \\
\hline Manyuro & 3 & 4 & 5 & 1 & 2 \\
\hline Sanga & 4 & 5 & 1 & 2 & 3 \\
\hline Singgul & 5 & 1 & 2 & 3 & 4 \\
\hline & Nong & Nong & Get & Gong & Cer \\
\cline { 2 - 7 } & & & & &
\end{tabular}

Tabel 4. Patet dalam Karawitan Sunda 
memunculkan lagu dan nuansa musikal yang berbeda pula. Begitulah seterusnya tentang proses pembentukan gending-gending yang terdapat dalam karawitan Sunda terutama dalam gendinggending yang embatnya sawilet dan dua wilet.

\section{Identifikasi Laras, Surupan, dan Gending dalam Sebuah Lagu}

Sebelum memulai praktik bermain gamelan saléndro, terdapat beberapa langkah yang harus diperhatikan oleh seorang pengrawit terutama oleh seorang perebab sebagai berikut.

\section{Identifikasi Laras}

Seorang pengrawit (khusus perebab) harus mengetahui terlebih dahulu laras dari lagu yang akan disajikan, berlaras saléndro, pélog, degung, madenda, atau mandalungan. Dalam karawitan Sunda, bisa terjadi satu lagu yang disajikan memiliki multi-laras, artinya terdiri dari laras campuran dari berbagai laras yang ada dalam karawitan Sunda. Pemahaman terhadap laras dari sebuah lagu sangat penting untuk diketahui terlebih dahulu oleh pengrawit, terutama bagi seorang perebab agar mudah menafsir teknik menggesek rebab dan garapnya. Jika lagu memiliki satu laras misalnya hanya laras saléndro, atau pélog saja, posisi penjarian dalam memainkan rebab tidak pindah-pindah. Akan tetapi, jika satu lagu memiliki beberapa laras, posisi penjarian rebab akan berpindahpindah menyesuaikan dengan lagu tersebut. Posisi penjarian sangat penting kaitannya dengan pembentukan tangga nada berbagai laras, untuk pembentukan nada tinggi maupun nada rendah. Hal ini akan mempermudah seorang perebab untuk menafsir lagu terutama untuk mengawali lagu (pangkat) atau gending.

\section{Identifikasi Surupan}

Setelah sebuah lagu diketahui larasnya, langkah selanjutnya mencari surupan dari lagu tersebut, surupan da (1) =Tugu, mi (2) = Tugu, na (3) = Tugu, atau $t i(4)=$ Tugu. Hal ini penting dilakukan untuk menyesuaikan lagu dengan perangkat gamelan saléndro yang digunakan. Kesesuaian titi laras rebab, lagu, dan gamelan dapat menghasilkan keharmonisan sajian terutama sebagai titincakan (tumpuan) pesinden dalam menyanyikan sebuah lagu. Irawan (2014: 21) mengungkapakan tentang surupan sebagai berikut.

Penguasaan surupan sangat menentukan kemampuan seorang vokalis (sinden dan $a l o k$ ) dan pemain rebab dalam membangun dan menguatkan rasa musikal terhadap lagu yang dibawakan serta dijalin bersama, sesuai dengan gending atau waditra pengiring lainnya. Gaya ungkap nyanyian pribadi sindén dan atau alok, maupun gaya ungkap rebaban perebab menjadi nampak dengan mengolah surupan secara kreatif dan cermat. Artinya, surupan maupun laras menjadi alat atau teknik untuk mengungkapkan ekspresi musikalitasnya.

Berdasarkan pendapat Irawan jelas bahwa surupan merupakan konsep musikal yang sangat penting untuk dikuasai oleh seorang pengrawit dalam membentuk ekspresi musikalitas yang sesuai dengan estetika dalam karawitan Sunda. Secara umum konsep surupan dalam permainan gamelan saléndro adalah memposisikan lagu yang dinyanyikan oleh pesinden agar tetap berada dalam wilayah (range) gamelan yang ada meskipun lagu tersebut berbeda laras dengan gamelan yang digunakan. Waditra yang bertugas untuk hal ini adalah waditra rebab. Hubungan surupan dengan posisi penjarian rebab adalah sebagai berikut.

Perbedaan surupan dari sebuah lagu, berdampak terhadap posisi penjarian rebab dengan menyesuaikan surupan tersebut. Rebab Sunda yang terdiri dari dua dawai/kawat rebab, biasanya dilaras menyesuaikan nada gamelan saléndro dengan nada $d a$ (1) dan $t i$ (4). Oleh karena itu, di dalam waditra rebab terdapat nada-nada mutlak laras saléndro sebagai tafsir dari gamelan saléndro dengan posisi penjarian nada Tugu (da/1) laras saléndro ditengkep oleh jari kelingking tangan kiri (Gambar 1).

Jika sebuah lagu berbeda laras dan surupannya dari gamelan saléndro misalnya laras degung $d a=$ Tugu, atau $m i=T u g u$, seorang perebab harus berupaya agar lagu yang berbeda larasnya dapat tetap berada dalam wilayah gamelan saléndro. Caranya adalah mengambil nada Tugu atau mempertahankan nada Tugu laras saléndro sebagai 
jembatan untuk masuknya laras lain. Sebagai contoh, laras degung surupan da (1) =Tugu berarti nada 1 laras degung sama dengan nada Tugu laras saléndro, maka posisi penjarian rebab mengalami perubahan posisi. Posisi jari kelingking yang awalnya nada Tugu (da laras saléndro) berubah menjadi nada da/1 laras degung (Gambar 2).

Contoh lain jika larasnya madenda surupan ti (4)=Tugu, nada $t i$ (4) laras madenda sama dengan nada Tugu (1) laras saléndro sebagai jembatannya. Dengan demikian, posisi penjarian rebab harus menyesuaikan laras madenda yaitu nada da (1) Tugu laras saléndro berubah menjadi nada $t i$ (4) laras madenda (Gambar 3).

\section{Identifikasi Gending dalam Konsep Patet}

Setelah diketahui laras dan surupan dari sebuah lagu yang akan disajikan dalam bermain gamelan saléndro, langkah selanjutnya adalah mengidentifikasi gending yang akan digunakan untuk mengiringi lagu tersebut. Tentunya untuk mengetahui gending, harus melihat terlebih dahulu konsep patet yang ada dalam tabel, seperti telah dijelaskan di atas.

Pengidentifikasian gending dapat berangkat dari sebuah lagu yang sudah diketahui laras dan surupannya yaitu dengan melihat kenongan dan gongan dari lagu tersebut. Sebagai contoh, jika sebuah lagu memiliki laras degung surupan mi (2)= Tugu, nada 2 ( $m i$ ) laras degung yang disajikan oleh vokal pesinden dan perebab sama dengan nada Tugu (1) laras saléndro dalam gamelan. Dengan demikian, terdapat dua nada yang tumbuk (bersamaan) antara laras degung dan laras saléndro yaitu nada 2 ( $m i$ ) laras degung dengan nada $1(d a)$ laras saléndro serta nada 5 (la) laras degung dengan nada 4 (ti) laras saléndro. Langkah selanjutnya melihat dalam tabel konsep patet, sehingga ada dua nada saléndro yaitu nada $d a$ (1) dan $t i$ (4), Nada 1 laras saléndro berfungsi sebagai kenongan (dominannya) sedangkan nada 4 laras saléndro berfungsi sebagai gongan (tonikanya).

Dalam konsep patet, posisi di atas berada pada posisi lagu I dan IV dalam patet nem. Oleh karena itu, berdasarkan tabel patet, nama gendingnya adalah Gending Gendu dengan posisi kenongan nada 1 (da) dan gongan nada $4(t i)$. Selanjutnya dapat diketahui bahwa pancer dari posisi I dan IV adalah nada 5, pangagetnya nada 3. Setelah gendingnya diketahui, maka lagu yang berlaras degung surupan 2=Tugu dapat diiringi gamelan saléndro dengan menggunakan gending Gendu Patet Nem yang arkuh lagunya 35313534 . Angka 3 berfungsi sebagai pangaget, angka 5 sebagai pancer, angka 1 sebagai kenong, dan angka 4 sebagai gong. Adapun pola tabuh bermain setiap waditra (Tabel 5).

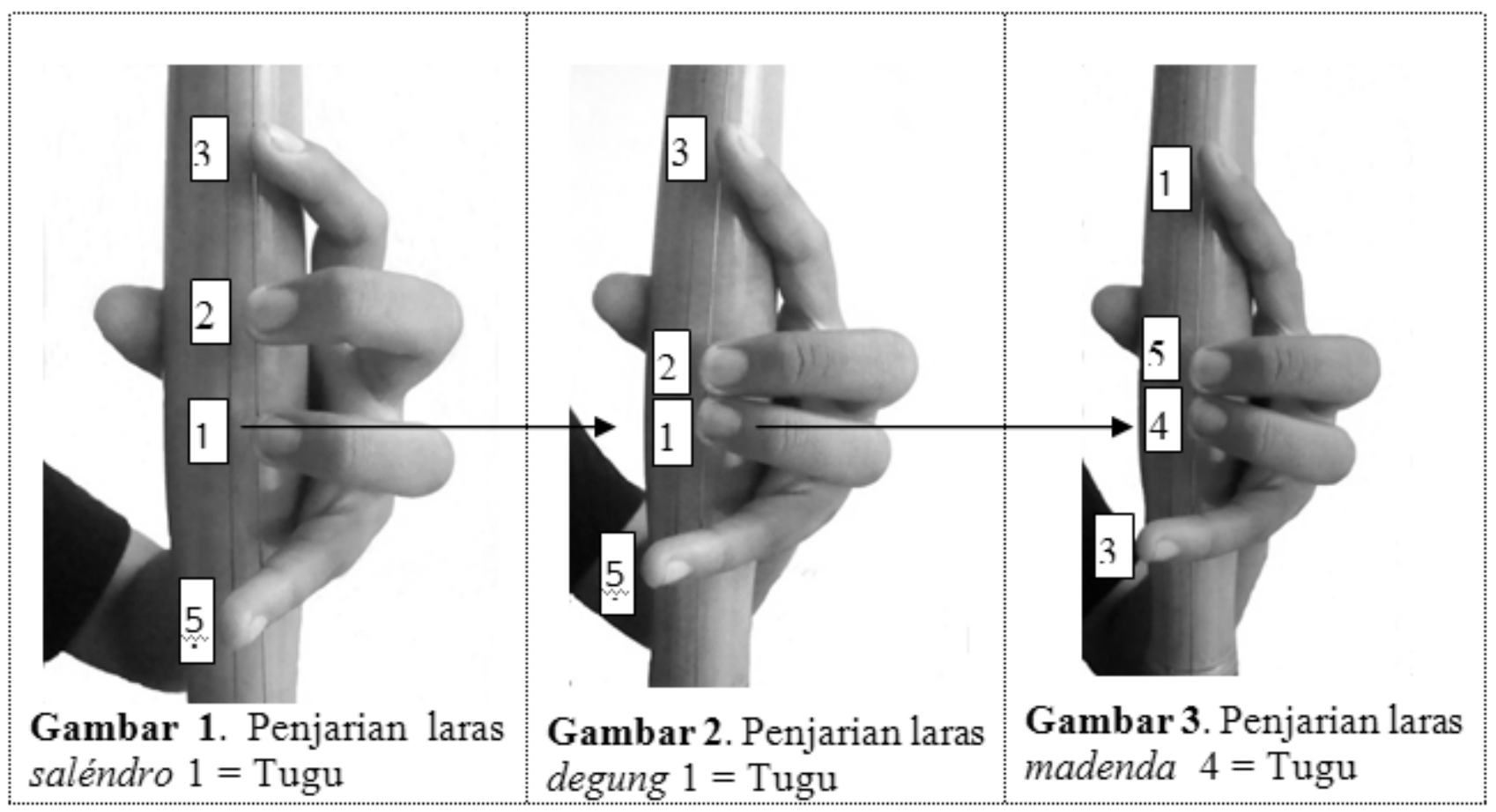


Pangkat: SR.I: $\quad \begin{array}{llllllll}3 & 1 & 2 & 4 & 5 & 3 & 4\end{array}$

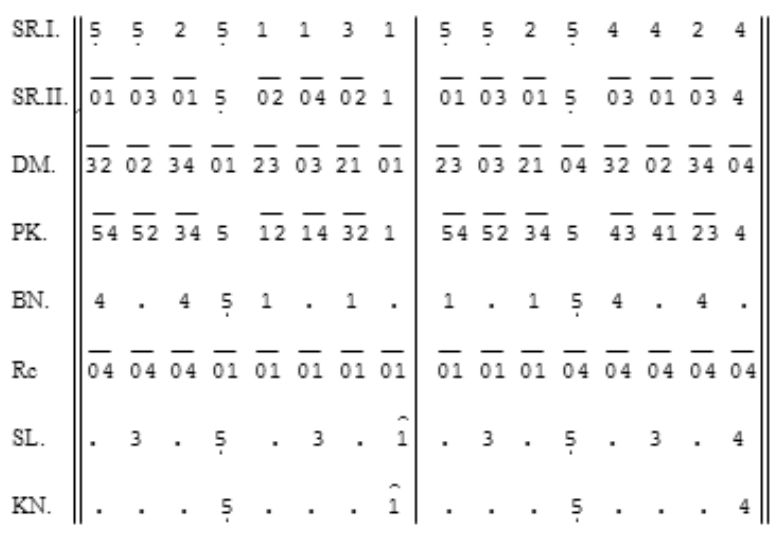

Tabel 5. Pola Tabuah tiap Waditra

Selanjutnya, pengidentifikasian lagu dalam laras dan surupan yang lain (seperti laras madenda dan mandalungan) sama seperti di atas. Beberapa lagu yang berbeda larasnya akan berbeda pula gending yang akan digunakan untuk mengiringinya, begitu pula sebuah lagu yang berbeda surupan-nya meskipun dalam laras yang sama, akan berbeda gending yang akan digunakan untuk mengiringinya. Dengan demikian, pengidentifikasian untuk menyajikan sebuah lagu dalam gamelan saléndro dapat diurut mulai dari lagu yang akan disajikan, identifikasi laras, surupan, gending, disusul pangkat rebab/saron, lalu pesinden menyanyikan lagu tersebut.

\section{Aplikasi Laras, Surupan, dan Patet dalam Sajian Gamelan Salendro}

Sebagai tahap akhir, selanjutnya digambarkan hubungan lagu, laras, surupan, dan patet dalam praktik menabuh gamelan saléndro dengan beberapa surupan dan nama gendingnya. Adapun lagu yang menjadi bahan analisis adalah lagu Langit Biru dengan pertimbangan bahwa lagu ini sangat populer dinyanyikan oleh para pesinden Sunda serta memiliki laras yang berbeda dengan laras gamelan saléndro yakni larasnya madenda surupan $\mathrm{ti}=$ Tugu. Lagu Langit Biru bisa disajikan dalam sajian jaipongan maupun kiliningan.

Lagu Langit Biru memiliki laras madenda surupan ti (4) = Tugu dengan Gending Senggot/ Panglima. Maknanya bahwa Lagu Langit Biru ini larasnya madenda dengan surupan ti = Tugu. Tugu yang dimaksud adalah nada Barang (atau nada 1) dalam laras gamelan saléndro. Jadi, nada 4 laras madenda dari lagu Langit Biru sama dengan nada Tugu/Barang (1) dalam gamelan laras saléndro. Selanjutnya, tangga nada lagu tersebut akan tersusun sesuai nada dasar yang ada, terus mengembangkan rangkaian atau variasi-variasi nadanya sesuai dengan kebutuhan lagu baik nada naik maupun turun (Tabel 6).

Berdasarkan tabel 6 terlihat bahwa nada $t i$ (4) lagu Langit Biru laras madenda berada pada nada $d a$ (1) laras saléndro yang terdapat dalam gamelan. Maka, terdapat tiga nada yang tumbuk (bersamaan) dari lagu Langit Biru yaitu nada 4 ( $t i$ ) laras madenda tumbuk dengan nada 1 (da) laras saléndro, nada 5 (la) madenda tumbuk dengan nada 2 ( $m i$ ) laras saléndro, serta nada 2 ( $m i$ ) laras madenda tumbuk dengan nada 4 ( $t i$ ) laras saléndro. Selanjutnya, ketiga nada tumbuk tersebut menjadi nada pokok yang berfungsi sebagai nada kenongan dan gongan dalam gamelan saléndro yang digunakan untuk mengiringi lagu tersebut. Dengan demikian, diketahui bahwa untuk mengiringi lagu Langit Biru, terdapat dua nada yang berfungsi sebagai kenongan yaitu nada Galimer/4 (ti) dan nada Barang/1 (da), sedangkan nada gongannya hanya satu yaitu nada Loloran/2 (mi) laras saléndro. Dengan diketahuinya nada yang berfungsi sebagai kenongan dan gongan, maka dapat diketahui gending untuk mengiringi lagu ini dengan melihat tabel patet. Berdasarkan tabel patet, gending Senggot/Panglima adalah gending yang memiliki kenongan nada Barang (1) dan Galimer (4) serta nada gongan Loloran (2) (lihat tabel patet).

\begin{tabular}{|l|l|l|l|l|l|l|l|l|l|l|l|l|l|l|l|l|l|l|l|l|l|l|l|l|l|l|l|l|}
\hline I & s & s & s & s & s & s & s & s & s & s & s & s & s & s & s & s & s & s & s & s & s & s & s & s & s & s & s & s \\
\hline R & 1 & & & & & 5 & & & & 4 & & & & 3 & & & & & 2 & & & & $\mathbf{1}$ & & & & & 5 \\
\hline M & B & & & & & S & & & G & & & P & & & & & L & & & B & & & & S \\
\hline D & & & 3 & & & & & & & 2 & & 1 & & & & & & & 5 & & & & $\mathbf{4}$ & & 3 & & & \\
\hline
\end{tabular}

Tabel 6. Pengembangan nada dalam lagu Langit Biru 


\section{LAGU LANGIT BIRU}

Laras madenda

surupan $\mathrm{Ti}(4)=$ Tugu

Laras: Madenda/Sorog

Notasi: Daminatila

\begin{tabular}{|c|c|c|c|c|c|c|c|c|c|c|c|c|c|}
\hline $\begin{array}{l}\text { Notasi } \\
\text { Lagu }\end{array}$ & - & . $\cdot$ & - & - & $\cdot$ & 54 & $\overline{3}$. & 54 & 3 & 5 & i (2) & $\begin{array}{l}\text { laras } \\
\text { madenda }\end{array}$ & $\dot{2}$ \\
\hline $\begin{array}{l}\text { Rumpaka/ } \\
\text { Sya1r }\end{array}$ & & & & & & $\mathrm{La}-$ & $i-t$ & la-ngi- & $t$ & bi & $-r u$ & Harmonis & $\operatorname{Tum}_{\text {-buk }}$ \\
\hline $\begin{array}{l}\text { Instrumen } \\
\text { Saron }\end{array}$ & 55 & 55 & 5 & 2 & 5 & 25 & 4 & 4 & 2 & 4 & 2 (4) & $\begin{array}{l}\text { laras } \\
\text { salendro }\end{array}$ & 4 \\
\hline
\end{tabular}

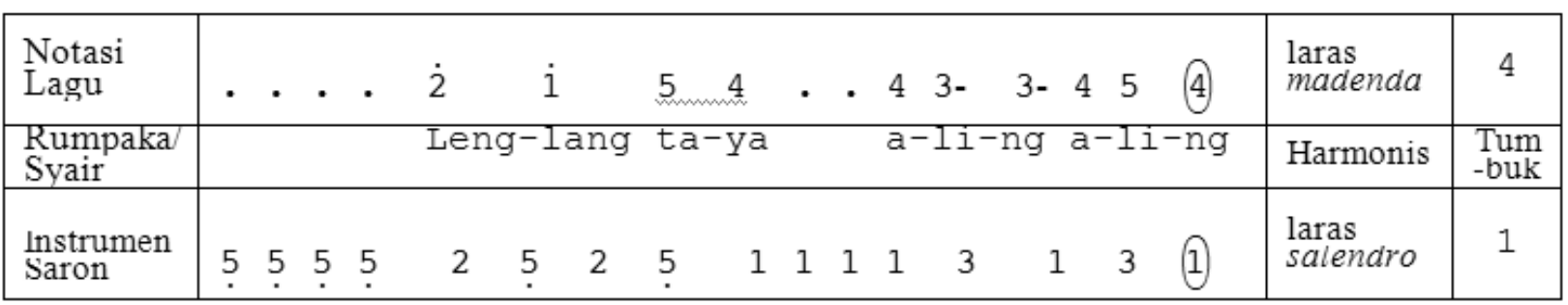

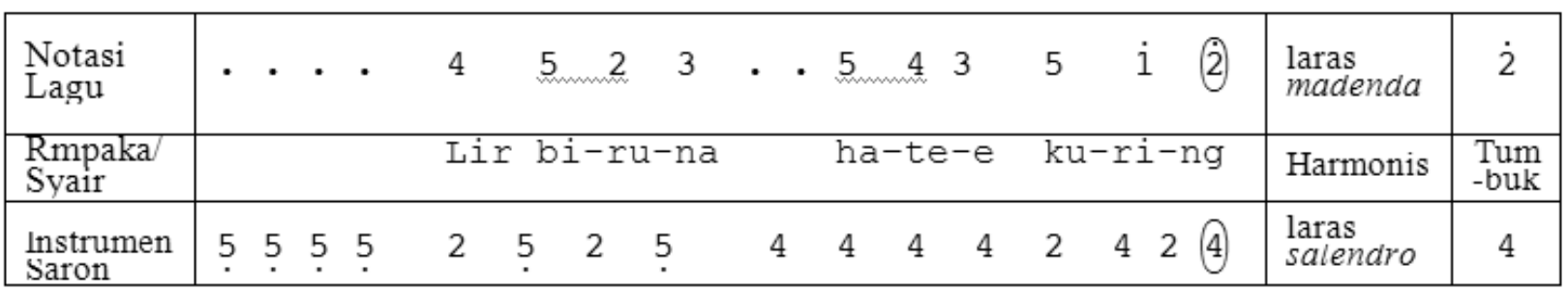

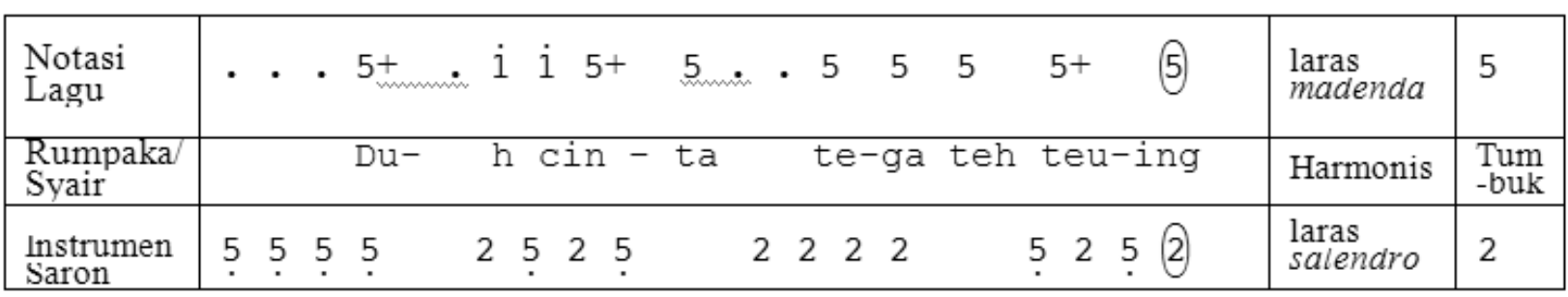

Meskipun Lagu Langit Biru larasnya berbeda dengan gamelan yang digunakan, namun tidak menimbulkan kejanggalan dalam permainan gamelan saléndro, malah sebaliknya perbedaan laras tersebut menimbulkan kesan harmonis yang dibentuk dari sebuah perbedaan laras. Keharmonisan kedua laras ini dapat terwujud karena arah konsepnya sama yaitu menggunakan konsep laras dan surupan dalam memainkan gamelan maupun menyajikan vokal. Hal tersebut menjadi keunikan dari sajian gamelan saléndro khususnya dan garapan Karawitan Sunda pada umumnya.

Selain menimbulkan keharmonisan, adanya konsep laras dan surupan dalam permainan gamelan saléndro dapat menimbulkan hal positif lainnya yaitu semakin luasnya lahan kreativitas bagi pesinden untuk menyuarakan vokalnya. Ketika gending dan lagu disajikan, pesinden tidak dibatasi oleh balungan (rangka) bermelodi yang dapat membatasi wilayah gerak vokal. Wilayah nada pesinden hanya dibatasi oleh nada kenongan dan gongan saja. Artinya, seorang pesinden dapat memainkan nada-nada atau lagu dengan lebih kreatif, mengolah laras yang berbeda, mengolah cengkok atau ornamentasi lagu meskipun laras gamelannya berbeda, dengan syarat kenongannya tetap jatuh pada nada gamelan sesuai dengan gending yang disajikan. Kenongan dalam gamelan bukan sebagai melodi, tetapi hanya batas-batas saja 
agar suara pesinden tetap berada dalam koridor surupan lagu dalam gamelan yang digunakan.

Penyajian gamelan saléndro dapat terjalin dengan baik karena konsep menabuh gamelan saléndro-nya sendiri yang terbuka. Keterbukaan konsep menabuh ini dapat membentuk keharmonisan tiga komponen unsur musikal yakni konsep laras, surupan, dan patet . Lagu yang disajikan oleh pesinden maupun perebab tidak dibelenggu oleh arkuh lagu (balungan gending) yang panjang yang biasa ditabuh oleh waditra bilah atau pencon, akan tetapi arkuh lagu hanya batas-batasnya saja, hanya mengejar nada kenongan dan gongan. Seperti terlihat dalam tabel 7 bahwa arkuh lagu yang ditabuh oleh waditra saron sangat bebas jalinan melodinya dari nada-nada dalam lagu Langit Biru, bahkan mungkin pula terkesan sangat jauh dari lagunya. Pada tahap ini, nada yang dikejar hanya nada kenongan atau gongannya saja sebagai nada tumbuk yang dihasilkan dari konsep surupan. Dampak positifnya, rebab dan vokal memiliki kebebasan tersendiri untuk mengembangkan ornamentasinya.

Peranan konsep surupan, patet, dan laras sangat penting dalam permainan gamelan saléndro agar terjadi keharmonisan nilai rasa musikal yang didapat baik oleh pengrawit maupun pesinden. Tanpa adanya ketiga konsep ini, rasanya sangat sulit untuk menyanyikan lagu-lagu Sunda ke dalam gamelan saléndro karena memiliki laras yang berbeda-beda. Peranan ketiga komponen ini terutama surupan, dapat mengharmoniskan arah melodi lagu dari pesinden dengan melodi gamelan yang digunakan meskipun berbeda sama sekali larasnya. Arah melodi lagu dengan melodi gamelan sebenarnya berjalan sendiri-sendiri, akan tetapi karena mengacu konsep surupan yang terdapat nada tumbuknya maka perbedaan melodi dari keduanya seolah-olah terhapuskan. Untuk memperjelas perbedaan arah melodi dari permainan gamelan dengan lagu pesinden, dapat digambarkan berikut.

a. Notasi lagu dan gamelan pada baris ke-1

\begin{tabular}{|c|c|c|c|c|c|c|c|c|c|c|}
\hline $\begin{array}{l}\text { Notasi } \\
\text { Lagu }\end{array}$ & . . . & . & . 54 &.$\overline{3}$. & $5 \quad 4$ & 3 & 5 & i (2) & $\begin{array}{l}\text { laras } \\
\text { madenda }\end{array}$ & $\dot{2}$ \\
\hline $\begin{array}{l}\text { Rumpaka/ } \\
\text { Syalr }\end{array}$ & \multicolumn{4}{|c|}{ La-ngi-t } & la-ngi- & $t$ & $\mathrm{bi}$ & $-r u$ & Harmonis & $\begin{array}{l}\operatorname{Tum}_{-\mathrm{buk}} \\
-\mathrm{sum}\end{array}$ \\
\hline $\begin{array}{l}\text { Instrumen } \\
\text { Saron }\end{array}$ & 555 & 2 & 525 & 4 & 4 & 2 & 4 & 2 (4) & $\begin{array}{l}\text { laras } \\
\text { salendro }\end{array}$ & 4 \\
\hline
\end{tabular}

Dari notasi lagu dan gamelan tersebut, digambarkan kontur melodinya sebagai berikut:

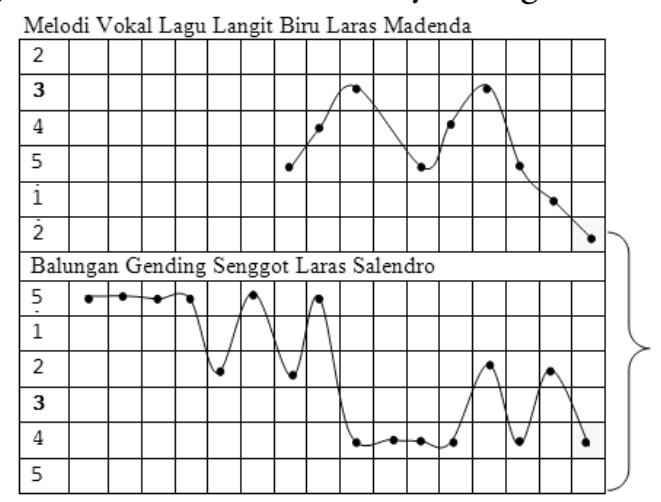

b. Notasi lagu dan gamelan pada baris ke-2

\begin{tabular}{|c|c|c|c|c|c|c|c|c|c|c|c|}
\hline $\begin{array}{l}\text { Notasi } \\
\text { Lagu }\end{array}$ & . . . & $\dot{2}$ & i & $5 \quad 4$ & . . & $43-$ & 3- 4 & 5 & & $\begin{array}{l}\text { laras } \\
\text { madenda }\end{array}$ & 4 \\
\hline $\begin{array}{l}\text { Rumpaka/ } \\
\text { Syair }\end{array}$ & & Leng & -1ang & ta-ya & & $a-1 i-n g$ & $g a-$ & $-1 i-$ & -ng & Harmonis & $\operatorname{Tum}_{-b u k}$ \\
\hline $\begin{array}{l}\text { Instrumen } \\
\text { Saron }\end{array}$ & 5555 & 2 & 2 & 1 & 11 & 1 & & 3 & (1) & $\begin{array}{l}\text { laras } \\
\text { salendro }\end{array}$ & 1 \\
\hline
\end{tabular}

Dari notasi lagu dan gamelan tersebut, digambarkan kontur melodinya sebagai berikut:

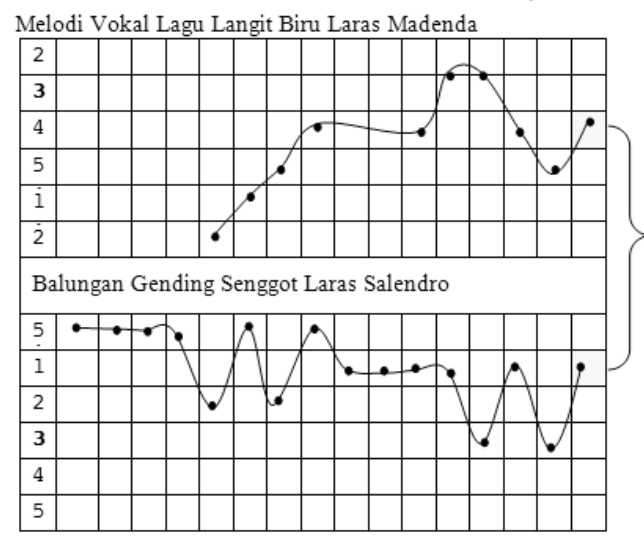

c. Notasi lagu dan gamelan pada baris ke-3

\begin{tabular}{|c|c|c|c|c|c|c|c|c|c|c|c|}
\hline $\begin{array}{l}\text { Notasi } \\
\text { Lagu }\end{array}$ & $\cdots$ & 4 & 5 & 2 & & . $\cdot$ & $5 \quad 43$ & 5 & i (2) & $\begin{array}{l}\text { laras } \\
\text { madenda }\end{array}$ & $\dot{2}$ \\
\hline $\begin{array}{l}\text { Rmpakal } \\
\text { Syair }\end{array}$ & & $\mathrm{Li}$ & $\mathrm{cb}$ & $i-r$ & $\mathrm{u}-\mathrm{na}$ & & ha-te-e & & u-ri-ng & Harmonis & $\begin{array}{l}\operatorname{Tum}_{\text {-buk }} \\
\end{array}$ \\
\hline $\begin{array}{l}\text { Instrumen } \\
\text { Saron }\end{array}$ & $\begin{array}{llll}5 & 5 & 5 & 5\end{array}$ & 2 & 5 & 2 & 5 & 4 & 4 & 2 & $\begin{array}{lll}4 & 2 & (4)\end{array}$ & $\begin{array}{l}\text { laras } \\
\text { salendro }\end{array}$ & 4 \\
\hline
\end{tabular}

Dari notasi lagu dan gamelan tersebut, digambarkan kontur melodinya sebagai berikut:

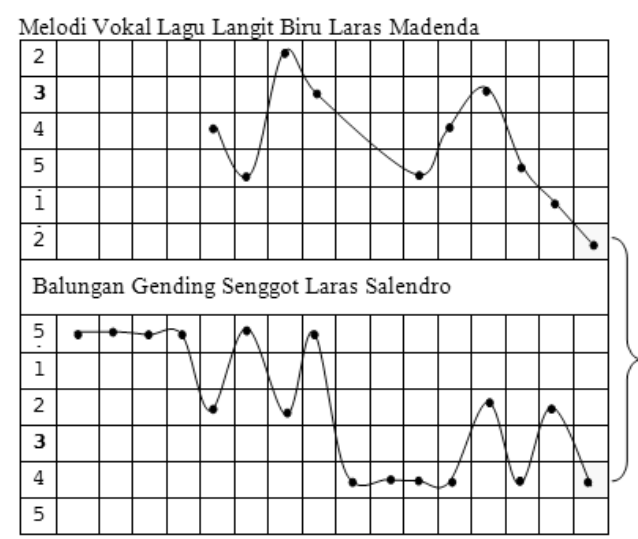


d. Notasi lagu dan gamelan pada baris ke-4

\begin{tabular}{|c|c|c|c|c|c|c|}
\hline $\begin{array}{l}\text { Notasi } \\
\text { Lagu }\end{array}$ & $\ldots 5^{+}$. i i $5^{+} 5$ & .. 55 & 5 & $5^{5+}$ & $\begin{array}{l}\text { laras } \\
\text { madenda }\end{array}$ & 5 \\
\hline $\begin{array}{l}\text { Rumpakal } \\
\text { Syair }\end{array}$ & $\mathrm{h}$ cin $-\mathrm{ta}$ & te-ga & teh & teu-ing & Harmonis & 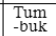 \\
\hline $\begin{array}{l}\text { Instrumen } \\
\text { Saron }\end{array}$ & $\begin{array}{llll}2 & 5 & 2 & 5\end{array}$ & $\begin{array}{llll}2 & 2 & 2 & 2\end{array}$ & & $5 \quad 2 \quad 502$ & $\begin{array}{l}\text { laras } \\
\text { salendro }\end{array}$ & 2 \\
\hline
\end{tabular}

Dari notasi lagu dan gamelan tersebut, digambarkan kontur melodinya sebagai berikut:

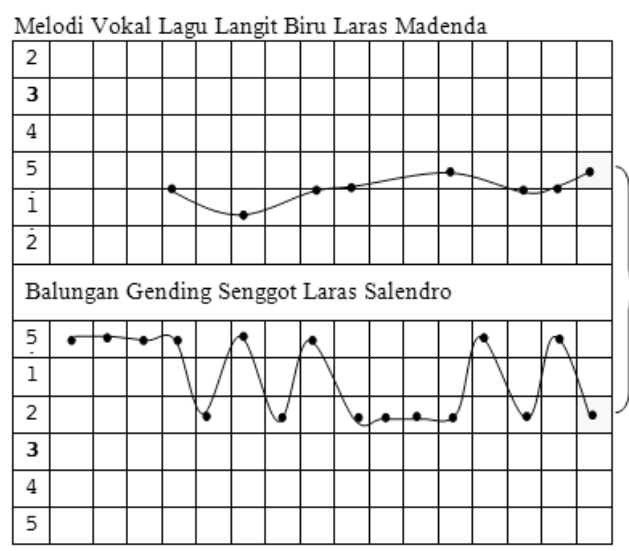

Berdasarkan grafik di atas dapat dilihat bahwa tidak ada kesamaan kontur melodi naik dan turun antara lagu Langit Biru dengan arkub lagu Gending Senggot yang digunakan untuk mengiringi lagu tersebut. Setiap baris tidak ada kesamaan kontur melodi yang terbentuk antara lagu Langit Biru dengan balungan pokok gending yang ditabuh oleh waditra saron. Pola menabuh gamelan saléndro tetap konstan, sedangkan vokal bisa bergerak bebas sesuai dengan kreativitas pesindennya. Hal ini menandakan bahwa lagu yang dinyanyikan oleh pesinden tidak dibingkai ketat oleh arkuh lagu sehingga memberi keleluasaan tersendiri bagi pesinden dalam mengembangkan senggol-senggol (ornamentasi) lagunya.

Perbedaan kontur melodi antara lagu dengan gending seperti di atas terjadi karena beberapa hal: pertama, perbedaan laras antara lagu dengan gamelan yakni lagunya berlaras madenda sedangkan gamelan berlaras saléndro; kedua, teknik permainan gamelan saléndro dalam karawitan Sunda memberikan ruang bebas kepada pesinden untuk berolah vokal karena tumpuan nada yang ditabuh oleh waditra gemelan pada prinsipnya hanya dua posisi saja yaitu nada kenongan dan gongan. Meskipun di dalamnya terdapat nada pangaget dan pancer yang ditabuh, akan tetapi kedua posisi ini dapat diabaikan/tidak menjadi keharusan. Hal ini terbukti ketika sebuah gending dimelodikan dalam sajiannya, kedua posisi ini terkadang tidak ditabuh karena tidak sesuai dengan alur melodi (naik dan turunnya melodi) atau dirasa kurang enak menurut rasa pengrawit. Meskipun demikian, terdapatnya berbagai perbedaan laras, kontur melodi, dan tangga nada yang dibentuk oleh vokal dan gamelan, bukan berarti tidak dapat menimbulkan sajian yang baik, akan tetapi sebaliknya dapat membentuk unsur harmonis dengan satu konsep yakni surupan. Konsep surupan-lah yang dapat mengikat kedua laras dan melodi atau tangga nada yang berbeda ini dapat terjalin harmonis ketika permainan gamelan saléndro disajikan. Konsep surupan pada intinya terdapat satu atau lebih nada yang sama frekuensinya (titi larasnya) atau nada dasarnya, sebagai jembatan penyambung bagi terjalinnya perbedaan laras dan melodi. Konsep di atas digunakan dalam sajian kiliningan, jaipongan, wayang golék, ketuk tilu, topéng banjét, bajidoran, dan celempungan.

\section{Penutup}

Berdasarkan uraian di atas, dapat disimpulkan bahwa terdapat keunikan pada penyajian gamelan saléndro dalam karawitan Sunda yang tidak ditemukan pada musik lain yaitu terdapat perbedaan laras antara gamelan yang digunakan dengan vokal pesinden yang dinyanyikan. Hal ini dapat terjadi karena peranan konsep laras, surupan, dan patet sebagai konsep musikal dalam karawitan Sunda. Peranan ketiga komponen ini sangat penting, saling terkait di antara ketiganya sehingga dapat membentuk sajian musikal yang harmonis meskipun dalam laras yang berbeda. Ketiga konsep ini sebagai kunci utama yang harus dikuasai seorang pengrawit (lebih khusus bagi seorang perebab) untuk menyajikan lagu atau gending, sebagai satu kesatuan yang utuh, memiliki keterkaitan satu sama lainnya dalam praktik menabuh gamelan saléndro. Pada aplikasinya, pengrawit tidak serta merta dapat meminkan gamelan saléndro dengan vokal pesinden sebelum memahami ketiga konsep ini. Seorang pengrawit harus memahami terlebih dahulu tentang laras dari lagu yang akan disajikan, surupan lagu, gending yang akan digunakan, serta pemahaman tentang prinsip menabuh setiap 
waditra yang sesuai dengan kaidah-kaidah dalam karawitan Sunda. Selain itu, teknik permainan gamelan saléndro yang bertumpu pada nada kenongan dan gongan, memberi ruang bebas kepada pesinden untuk mengolah ornamentasi vokalnya. Meskipun laras vokal dan gamelan berbeda, tetapi ketika disajikan tetap dapat terjalin harmonis sesuai dengan estetika dalam karawitan Sunda.

\section{Kepustakaan}

Hardjito, Dwi. 2000. "Pemakaian Matriks "Makro" Slendro Mikro untuk Menganalisis Skema Laras Musik Berbagai Bangsa" dalam PANGGUNG JURNAL SENIDANBUDAYA, Vol. XIV-Juni 2000; 128-160.

Hastanto, Sri. 2009. Konsep Pathet dalam Karawitan Jawa. Surakarta: ISI Press Surakarta.

Herdini, Heri. 2003. "Peninjauan Ulang terhadap Teori Laras dan Surupan Karya Raden Machyar Anggakusumadnata" dalam PANGGUNG JURNAL SENI DAN BUDAYA, Vol. XXXII, 2003: 54-66.

- 2007. Raden Machyar Angga Koesoemadinata: Pemikiran dan Aktivitasnya dalam Dunia Karawitan Sunda. Bandung: Sunan Ambu Press.

2008. "Studi Kasus tentang Konsep Surupan dalam Praktik Karawitan Sunda." [Laporan Penelitian], STSI Bandung.

Hermawan, 2002. Deni. Etnomusikologi: Beberapa Permasalahan dalam Musik Sunda. Bandung:
STSI Press.

Irawan, Endah. 2014. "Karakter Musikal Lagu Gédé Kepsesindenan Karawitan Sunda" dalam RESITAL: JURNAL SENI PERTUNJUKAN, Volume 15 No. 1 Juni 2014; 18-31.

Koesoemadinata, 1969. RMA. Ilmu Seni Raras. Djakarta: Pradnja Paramita.

Prasetya, Hanggar Budi. 2012. "Pathet: Ruang Bunyi dalam Karawitan Gaya Yogyakarta" dalam PANGGUNG JURNAL SENI DAN $B U D A Y A$, Volume 22, No.1-Januari-Maret; 67.

Saepudin, Asep. 2007. "Tafsir Ulang atas Hasil Kajian Ulang Teori Laras dan Surupan Karya RMA. Koesoemadinata." dalam PANGGUNG JURNAL SENI DAN BUDAYA, Volume 17. No. 1 Februari-Mei 2007; 23-32.

Sasaki, Mariko. 2007. Laras Pada Karawitan Sunda. Bandung: P4SP UPI.

Soepandi, Atik. 1995. Kamus Istilah Karawitan Sunda.Cetakan Kedua. Bandung: CV. Satu Nusa.

Suhardjono dan Trikoyo. 2011. "Karawitan Pakeliran Gaya Kedu Bagelen”. RESITAL: JURNAL SENI PERTUNJUKAN, Vol. 12. No. 1, Juni 2011; 67.

Sukistono, Dewanto. 2014. "Pengaruh Karawitan terhadap Totalitas Ekspresi Dalang dalam Pertunjukan Wayang Golek Menak Yogyakarta” dalam RESITAL: JURNAL SENI PERTUNJUKAN, Vol. 15. No. 2, Desemeber 2014; 180. 